\title{
Eat To Live or Live To Eat? Do Parents and Children Agree?
}

\author{
Armelle Le Bigot Macaux* \\ AB/C+ 100 Avenue Charles de Gaulle, 92522 Neuilly - sur-Seine Cedex, Paris
}

\begin{abstract}
The lifestyles and diets of children in developed countries is changing rapidly in response to the social and cultural climate, as well as the availability of an increasing range of foods. The aim of this on-going study is to assess the trends in food-related behaviours of children and their attitudes towards food and nutrition. The study also monitors markers for physical activity, which have been presented elsewhere (Bellisle et al, 2000). Three successive surveys (1993, 1995, and 1997) were carried out on samples of 1000 French children aged 9-11 years and their mothers.

Results: Attitudes towards food varied markedly between children and their mothers. Children viewed food primarily as a necessity of life, whereas mothers viewed food primarily as a pleasure for their child, with necessity and nutrition given a lower importance. Contrary to popular belief children's enjoyment of 'unhealthy' and 'healthy' foods was similar. French-fries were the favourite food for $92 \%$ of children, closely followed by pasta (89\%). Fruit and candy received similar scores $(82 \%$ and $81 \%$ respectively), suggesting that external factors such as convenience are the prime barrier to fruit consumption rather than the enjoyment factor. Over the three surveys a strong persistence of the traditional French meal pattern has been demonstrated, with breakfast, lunch and evening meals eaten by $97 \%$, 96\% and $99 \%$ of children respectively. One increasing occurrence is the viewing of television during meal times with $25 \%$ of breakfasts, $46 \%$ of afternoon snacks and $41 \%$ of evening meals consumed in front of the television. Children's attitudes towards food demonstrated an overwhelming trust of their mother and her ability to provide them with nourishing foods. Mothers often found it difficult to reconcile the demands of family life, employment, healthy eating and the maintenance of a pleasurable atmosphere at mealtimes.

Conclusions: Overall, children and mothers appeared to have divergent attitudes towards food. An understanding of children's enjoyment of foods considered more 'healthy' or less 'healthy' enables effective nutrition messages to be developed for children. However, further work is needed to explore the long-term impact of mothers' attitudes towards food and mealtimes on a child's relationship to food and eating habits during adolescence through to adulthood.
\end{abstract}

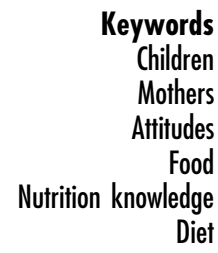

\section{Introduction}

Over the past decade $\mathrm{AB} / \mathrm{C}+$, a Paris based international marketing consultancy that specialises in children and teenage issues, in conjunction with INSERM and Kellogg's, has carried out a barometer-type survey of children's attitudes towards nutrition. Surveys have been carried out every 2 years since 1993 (fieldwork in 1993, 1995 and 1997). Surveys will now continue every 4 years starting from 1997, the next fieldwork phase will take place in 2001. Additional in depth qualitative research has also been carried out to explore mothers' relationships with food and the influence of this on feeding their children.
This article will examine the attitudinal aspects of the survey, provide an exploration of the differences in attitudes between children and their mothers regarding food, mealtimes and eating, and provide an insight into the understanding of nutrition by French children. Unless otherwise stated figures quoted are from the most recent 1997 survey.

\section{Methods}

The surveys were conducted on sample groups of approximately 1000 children aged 9-11 years (and their mothers), selected to be socio-demographically representative of the French population. Full details of the survey 
Table 1 Children's favourite foods versus healthy foods

\begin{tabular}{lcl}
\hline Foods most liked & \% children $97(95,93)$ & Foods considered to be most healthy \\
\hline French Fries & $92(93,92)$ & Vegetables \\
Pasta & $89(87,86)$ & Fruits \\
Ice cream & $88(90,86)$ & Orange juice \\
Orange juice & $87(87,86)$ & Milk \\
Nutella spread & $87(84,80)$ & Yoghurt \\
Chicken & $86(86,83)$ & Cheese \\
Chocolate & $86(86,84)$ & Meat \\
Croissants & $86(85,84)$ & Fish \\
Pizza & $85(83,81)$ & Raw vegetables \\
Cake & $83(84,83)$ & Salad \\
Fruits & $82(80,79)$ & Cornflakes \\
Candy & $81(81,78)$ & Bread \\
\hline
\end{tabular}

methodology and results have been published elsewhere ${ }^{1}$

The aim of the most recent survey was to assess and follow up food-related behaviours and measures of both activity and inactivity. Children were interviewed alone and answered structured questionnaires relating to food consumption, food preferences and awareness of nutritional terms. The questionnaire used was similar to the previous surveys in 1995 and 1993.

In addition parents were interviewed, in the absence of their child, with regard to the child's daily habits, meals, height and weight. Socio-demographic data were also collected. Parental attitudes concerning food, health and nutrition were included in the survey. The majority of interviews were conducted with mothers, as in French society they retain the traditional role of food purchase, preparation and education within the family structure. Few French fathers undertake responsibility for food provision within the family and therefore, the results presented reflect the understanding and attitudes of mothers towards their children's diets.

\section{Results}

\section{Attitudes Towards Food and Meals}

Children and their mothers viewed food quite differently. In order of importance, children viewed food as a necessity of life, vital for maintenance of the body and as a pleasure. Food was perceived by children as necessary to stay alive, to eat and fill one's stomach, and to satisfy a need. In terms of body maintenance, food was deemed necessary to grow, to keep in shape, to be strong, to have energy and be active. Statements referring to foods as 'good things', 'delicious' and 'treats' expressed the concept of food as a pleasure.

In contrast, mothers' understanding of what food meant to their child was the opposite of the rankings made by the children. Mothers reported food primarily to be a pleasure (70\%), a necessity for life (26\%), as a constraint (19\%) and as a means to meet nutritional needs (18\%). Food as a pleasure included enjoyment of eating, preparing and sharing food. Nutritional concerns focussed on making well-balanced meals, staying healthy and using fresh and natural products. The time required for shopping and arguments within the family concerning food preferences were considered constraining factors because of the limited time available during the daily routine. Food was viewed by the mothers as the basis of family life, providing a foundation for time spent together, and not only as a necessity to maintain life.

\section{Best Liked Foods versus Healtby Foods}

The 12 foods best liked by children and those considered to be most healthy are listed in Table 1 . While there are discrepancies between the foods children considered 'tasty' and those classified as 'most healthy', taste and health were not necessarily opposed. For instance the food that children considered to be most 'tasty', fried potatoes (92\%), was closely followed by 'healthy' foods such as pasta (89\%), orange juice (87\%) and chicken (86\%). Fruit and candy achieved similar taste scores, (82\% and $81 \%$ respectively).

The foods considered least healthy were sugar (6\%), salt (6\%), mayonnaise (5\%), salad dressing (5\%), sweets $(5 \%)$, sodas (5\%), ketchup (3\%), wine (2\%) and mustard (1\%).

\section{Attitudes towards meals}

Almost all children consumed 3 meals each day, with 97\% eating breakfast, 96\% eating lunch and 99\% eating dinner. In addition, $86 \%$ of children consumed an afternoon snack (traditionally viewed as a fourth meal for children in France). An increasingly common occurrence is television watching during meals, with $25 \%$ of breakfasts, $46 \%$ of afternoon snacks and $41 \%$ of evening meals consumed in front of the television.

Children's favourite meals were equally distributed with respect to the four meals of the day. $43 \%$ of the children surveyed identified their preferred choice of meal as a 'pleasure', especially at breakfast (13\%) and the afternoon snack (17\%). 15\% identified 'nutrition and abundance' as reasons for preferring breakfast. 'Family 
Table 2 Children's attitudes to meals and food choice

\begin{tabular}{|c|c|c|c|}
\hline Statement & $\begin{array}{c}1997 \\
\% \text { agree }\end{array}$ & $\begin{array}{l}1995 \\
\% \text { agree }\end{array}$ & $\begin{array}{l}1993 \\
\% \text { agree }\end{array}$ \\
\hline Mom is a good cook; I like eating what she makes & 90 & 92 & 91 \\
\hline $\begin{array}{l}\text { I don't worry too much about what I have to eat to stay healthy; } \\
\text { my mom takes care of that }\end{array}$ & 86 & 84 & 83 \\
\hline $\begin{array}{l}\text { I like to have my meals with my parents, because it is } \\
\text { an opportunity for us to talk }\end{array}$ & 82 & 81 & 80 \\
\hline Lunch is good and it's the time of day when I'm the most hungry & 74 & 74 & 72 \\
\hline I like afternoon snacks because I can eat what I like & 73 & 70 & 70 \\
\hline $\begin{array}{l}\text { When I don't like something, I'm often forced to eat it anyway because } \\
\text { my mom says that I have to eat all kinds of foods }\end{array}$ & 71 & 70 & 69 \\
\hline I would like to have more time for breakfast in the morning & 66 & 73 & 68 \\
\hline Cafeteria food at school is not very good & 52 & 49 & 50 \\
\hline In the morning I prefer to prepare my own breakfast & 48 & 48 & 44 \\
\hline $\begin{array}{l}\text { Dinners take too long: I would rather do something else than } \\
\text { stay at the table }\end{array}$ & 41 & 39 & 42 \\
\hline My mom doesn't like me to snack during the day so I do it in secret & 34 & 33 & 33 \\
\hline I prefer to eat at the cafeteria because of my friends & 31 & 30 & 31 \\
\hline Sometimes I get into fights with my mom about food because we don't have the same tastes & 31 & 31 & 22 \\
\hline At the cafeteria, I can eat what I want & 25 & 20 & 23 \\
\hline We watch television at dinner time much too often & 20 & 21 & 21 \\
\hline
\end{tabular}

time together' was given as a reason for preferring dinner. The meal viewed by children as the most important meal of the day was breakfast (61\%), followed by lunch (24\%), dinner (12\%) and the afternoon snack (4\%). There was a dramatic increase of $14 \%$ in the understanding of the importance of breakfast compared to 1993.

When provided with a choice of menus $76 \%$ children reported that the traditional three-course French meal was best for health, while only a minority (3\%) in each sample had the same opinion of the typical 'fast food' menu. Children do not necessarily prefer 'fast food' to traditional meals, with 35\% reporting a preference for 'fast food' and $33 \%$ preferring a traditional meal.

Children's attitudes towards meals and food demonstrated an overwhelming trust of their mother and her ability to provide nourishing foods (Table 2). 90\% of the children reported enjoying their mothers' cooking and $86 \%$ did not worry about what they ate as their mother was taking care of their food and health. Children occasionally had to succumb to parental pressure and eat foods that they did not really like (71\%) and one third reported fighting with their parents about food (31\%). According to the children the most common parental advice given was not to eat sugar and sweets, however one third ignored this request and snacked in secret (34\%).

\section{Children's understanding of nutrition}

Children were asked questions relating to their knowledge and understanding of terms associated with diet and healthy eating and individual components of the diet such as vitamins, protein and energy (Table 3). Overall children demonstrated a good understanding of basic healthy eating messages. For example, eat a variety of foods, reduce fat intake and that occasional consumption of unhealthy foods does not cause harm. Differences in understanding displayed by the three samples were small. There has been a gradual increase in understanding that exercise requires consumption of starchy foods (75\% in 1997, 72\% in 1995 and 67\% in 1993), and in agreement that enjoying what you eat is really important $(57 \%$ in 1997 up by 8\% from 1993).

However, an understanding of the more detailed aspects of nutrition was variable (Table 4). Children often knew and could at least partly explain the meaning of words such as vitamins, diet, vegetarian, fats, 'light', calcium and iron. Knowledge of other terms such as protein, lipids and fibre was much lower. Between the

Table 3 Children's understanding of 'healthy eating' messages

\begin{tabular}{|c|c|c|c|}
\hline \multirow[t]{2}{*}{ Statement } & \multicolumn{3}{|l|}{1997} \\
\hline & True & False & Did not know \\
\hline One must avoid eating too much fat & $95 \%$ & $5 \%$ & - \\
\hline In order to stay healthy, one must eat a bit of everything & $79 \%$ & $21 \%$ & - \\
\hline Dinner should be a light meal & $76 \%$ & $24 \%$ & - \\
\hline If you engage in sports, then you should eat starchy foods & $75 \%$ & $22 \%$ & $2 \%$ \\
\hline Occasional intake of unhealthy foods is not a problem & $66 \%$ & $34 \%$ & - \\
\hline What is really important is to enjoy your food & $57 \%$ & $43 \%$ & - \\
\hline You can eat as many sweets as you like provided you brush your teeth afterwards & $39 \%$ & $61 \%$ & - \\
\hline You can eat whatever you want as everything is good for you & $22 \%$ & $77 \%$ & - \\
\hline
\end{tabular}


Table 4 Children's understanding of nutrition

\begin{tabular}{|c|c|c|c|c|c|c|}
\hline & \multicolumn{6}{|c|}{ Year of Survey } \\
\hline & \multicolumn{2}{|c|}{1997} & \multicolumn{2}{|c|}{1995} & \multicolumn{2}{|c|}{1993} \\
\hline & Knew & Could explain* & Knew & Could explain* & Knew & Could explain* \\
\hline Vitamins & $98 \%$ & $84 \%$ & $98 \%$ & $81 \%$ & $98 \%$ & $80 \%$ \\
\hline Diet/regime & $84 \%$ & $96 \%$ & $93 \%$ & $96 \%$ & $96 \%$ & $95 \%$ \\
\hline Vegetarian & $83 \%$ & $93 \%$ & $81 \%$ & $90 \%$ & $80 \%$ & $89 \%$ \\
\hline Fats & $83 \%$ & $88 \%$ & $84 \%$ & $79 \%$ & $85 \%$ & $81 \%$ \\
\hline Calcium & $80 \%$ & $63 \%$ & $77 \%$ & $54 \%$ & $80 \%$ & $51 \%$ \\
\hline Iron & $77 \%$ & $69 \%$ & $79 \%$ & $64 \%$ & $83 \%$ & $65 \%$ \\
\hline Colourings & $71 \%$ & $88 \%$ & $71 \%$ & $81 \%$ & $78 \%$ & $80 \%$ \\
\hline Calories & $59 \%$ & $49 \%$ & $63 \%$ & $46 \%$ & $62 \%$ & $47 \%$ \\
\hline Light/diet & $52 \%$ & $87 \%$ & $61 \%$ & $85 \%$ & $71 \%$ & $89 \%$ \\
\hline Energy & $50 \%$ & $93 \%$ & $50 \%$ & $93 \%$ & $49 \%$ & $89 \%$ \\
\hline Preservatives & $47 \%$ & $79 \%$ & $45 \%$ & $78 \%$ & $49 \%$ & $79 \%$ \\
\hline Magnesium & $47 \%$ & $33 \%$ & $50 \%$ & $29 \%$ & $49 \%$ & $28 \%$ \\
\hline Minerals & $46 \%$ & $41 \%$ & $53 \%$ & $36 \%$ & $58 \%$ & $37 \%$ \\
\hline Protein & $38 \%$ & $31 \%$ & $41 \%$ & $31 \%$ & $44 \%$ & $29 \%$ \\
\hline Organic & $38 \%$ & $68 \%$ & $39 \%$ & $64 \%$ & $42 \%$ & $66 \%$ \\
\hline Phosphorous & $35 \%$ & $34 \%$ & $31 \%$ & $31 \%$ & $30 \%$ & $24 \%$ \\
\hline Simple sugars & $35 \%$ & $65 \%$ & $32 \%$ & $58 \%$ & $21 \%$ & $63 \%$ \\
\hline Nutrition & $32 \%$ & $67 \%$ & $28 \%$ & $79 \%$ & $26 \%$ & $71 \%$ \\
\hline Fibre & $30 \%$ & $80 \%$ & $33 \%$ & $23 \%$ & $41 \%$ & $27 \%$ \\
\hline Complex carbohydrate & $25 \%$ & $58 \%$ & $23 \%$ & $65 \%$ & $18 \%$ & $63 \%$ \\
\hline Dietetic & $23 \%$ & $60 \%$ & $26 \%$ & $51 \%$ & $30 \%$ & $57 \%$ \\
\hline Lipids & $22 \%$ & $28 \%$ & $24 \%$ & $27 \%$ & $30 \%$ & $29 \%$ \\
\hline
\end{tabular}

* \% of children who knew the term

years 1993 and 1997 a significant decrease occurred in children's awareness of the terms diet (84\% in 1997 compared to $96 \%$ in 1993), allergy ( $52 \%$ in 1997 compared with $71 \%$ in 1993) and fibre (30\% in 1997 compared to $41 \%$ in 1993).

The main sources of information about food and health spontaneously reported by children were parents (78\%) and schoolteachers (39\%). Other sources reported less often included television (14\%), doctors (10\%), friends (4\%), advertising (3\%) and food packaging (2\%).

\section{Gender differences}

Few gender differences were apparent in the survey. However, important differences were identified in sporting activities. More boys than girls were participating in sports outside of school ( $75 \%$ compared to $59 \%$ ), and more boys than girls undertook sports for at least $2 \mathrm{~h}$ each week (56\% compared to $32 \%$ ). Important differences in preferences for fruit and vegetables were also found, with more boys disliking raw vegetables than girls $(17 \%$ compared to 9\%) and fruit consumed more often by girls than boys (23\% compared to $17 \%$ ). Fewer girls than boys believed that chocolate to be healthy ( $6 \%$ compared to $20 \%$ ).

\section{Attitudes of motbers towards food and bealth}

Mothers were questioned regarding the words they most associated with food. Responses can be summarised into categories: pleasure (59\%), health (59\%), balance (53\%) and being together $(51 \%)$.

Important sources of information about food and health for the mothers included magazine articles (29\%), television programmes (27\%), doctors (27\%), friends (24\%), books (19\%), TV advertising (15\%) and food packaging (12\%). The information children learnt from school was spontaneously listed by $3 \%$ of mothers in 1997 , but after prompting this increased to $26 \%$, equal to television and doctors.

Additional qualitative interviews have been carried out by $\mathrm{AB} / \mathrm{C}+$ during 1997 to further explore mothers' attitudes towards food, their relationship with food and the influence that this has on the diets of their children. Forty double-interviews were carried out with mothers and their children (aged 6-12 years) and with 16 groups of 8 mothers and 8 children (aged 7-12). Half of the interviews were conducted in Paris and half in Tours (a small, traditional French Town).

On the basis of these interviews mothers have been defined into seven different types according to:

- The mother's relationship with the family's diet

- Their relationship with children with regards to food

- The children's response to the maternal behaviour

This typology relates purely to the mothers' attitudes to food. Mothers were grouped according to the degree of involvement with their children's diets and their behaviour: whether a mother's beliefs and needs were dictated to the child, or whether instead the needs and desires of the child were allowed to dictate the family's eating habits. Analysis has been carried out purely in terms of current relationships to food and the response of children to their mothers' attitudes to food. No attempt has been 
made to explore the long term impact of the 'mother type' on the children's relationship with food as they begin to gain independence from the family and establish their own food habits.

The seven mother typologies defined in this study are:

1. The Health Conscious Type - are very concerned about food and believe that a healthy body is dependant on eating well. They read food labels and look for specific qualities in a food. They attempt to control what their children eat by imposing their beliefs onto their children. Children either adopt the mother's advice, but miss the 'less healthy' foods excluded from the healthy regimen, or they rebel and food becomes a source of conflict. Children seek freedom in opportunities to consume food outside of the home, e.g. school meals.

2. The Mother Hen Type - believe that enjoyment and social aspects of food are of primary importance. Mealtimes are seen as an opportunity for bonding and making everybody happy. These mothers are attentive to the needs of the family and the need for variety and satisfaction. Relationships with food may either be flexible and pleasurable, or may be an extension of a tight emotional relationship with the child. Where flexible rules are applied the children respond positively with enjoyment and sharing.

3. The Busy Bees - food is part and parcel of the work involved in motherhood. They follow few nutritional principles: their main objective is to feed everyone in the best possible way, but generally have an overall desire to eat better. Food is part of education and behaviour. Rules about food are imposed in a fairly authoritative manner, i.e. you will eat what is on your plate or go without. Children respond either with obedience or conflict.

4. The Frustrated Greedy Type - find themselves in constant conflict with food. Food represents total enjoyment and they tend to alternate between periods of overeating followed by abstinence. The nutritional answer to their worries is to avoid the products they consider their downfall. The food rules for the children often reflect the mother's conflict with food, varying from day to day. The children's response varies according to the degree of restriction imposed by the mother at that point in time.

5. The Distant Type - view food as a necessary constraint in life. The role of food is to satisfy a need that cannot be met in any other way. The lack of interest in food shown by the mothers is reflected in meals fed to the child, often quick and easy meals involving minimal preparation and eating time. Children appear to replicate the mother's attitudes, believing that food is a necessity and not a source of enjoyment.

6. The Anxious Type - enjoy food, cooking and appreciate a wide variety of foods and tastes. They tend not to have particular nutritional priorities. Meals may be a source of conflict when the child displays limited interest in the foods presented. These mothers are anxious about the child's eating habits and their abilities as a mother to fulfil their child's nutritional needs. The children generally do not view food as a problem and enjoy their mothers' relaxed attitude towards meals, but may be sensitive to their mother's anxieties.

7. The Hesitant Type - the relationship with food is dictated by their lifestyle and a conflict between the demands of working and their duty to feed their family well. These mothers try to make their lives easier by using ready-to-eat or quick meals, but retain a fantasy of real meals and the whole family around the table together, which never really happens. They have a few broad principles on how children should be fed (e.g. children should drink milk for calcium), but they apply them in a very haphazard way. The children do not have any real concerns about food, but they often eat on their own and without social interaction from parents or siblings.

This exploration of the typology of mothers' with regards to their relationship with food opens a whole new field of exploration in terms of food behaviour. This study is the first of its kind and requires further work to track how over time the powerful notions held by the mothers translate into future trends. For example, the meals consumed within the home or social interactions within the family, and how these are translated by the children into values and reference points for their own eating habits.

\section{Conclusions}

In general the traditional French pattern of eating persisted among both the children and mothers surveyed, although there were signs of an increasing trend towards television viewing as a social accompaniment to meals and decreasing family interaction. In the 1995 survey a specific analysis was done to examine potential relationships between different aspects of lifestyle and an association between hours spent watching television and body mass index was observed ${ }^{1}$. It is not possible to determine whether television viewing during meal times has any contribution towards adiposity. However, a dichotomy exists between the emphasis placed by mothers on the role of meals as the foundation of family life and the apparent increase in television viewing during meals. Although not directly measured in these surveys it can be assumed that the extent of family interaction during 'TV meals' is likely to be reduced compared to meals eaten solely in each other's company.

Almost one third of mothers viewed food as a 
constraint because of the burden of planning, shopping for and preparing food. The additional qualitative research demonstrated a wide variability in mothers' feelings about food and diversity in priorities: from meeting nutritional needs to satisfying individual preferences; from maintaining family mealtimes as a haven of calm to merely providing food as duty of motherhood. Despite the apparent wide ranging internal conflict regarding food, children retain an all-encompassing trust in their mothers to provide the foods that are good for them and will meet their nutritional requirements.

Comparison of the foods most enjoyed by children with those foods perceived as healthy challenges the myth that children only enjoy 'junk' foods. Equal numbers of children would choose a traditional meal to a meal of burger and chips. Many of the foods ranked highly by children in terms of taste fit ideally into a varied healthy diet (e.g. pasta, orange juice and chicken). It was also surprising to note that children viewed fruit and candy equally in terms of taste. Efforts to promote fruit consumption among children need not necessarily regard taste as a potential obstacle, but should perhaps address other factors such as availability or convenience.

French school aged children continue to maintain a traditional meal pattern of 3 meals per day, plus an afternoon snack. They do not appear to be following the trend towards 'grazing' seen in some other countries throughout the world.

Children overwhelmingly demonstrated an eagerness to learn about their bodies, food and nutrition. The importance of capitalising on this willingness to learn at an age where food habits are still being established should not be underestimated. This survey has demonstrated that while children have an understanding of the basic healthy eating messages, overall knowledge of nutrition is generally poor. It is commonly accepted that education about food and health make an important impact when delivered during childhood. Therefore, it is essential that we match children's enthusiasm to learn about nutrition with both interesting and challenging nutrition education programmes.

As suggested by the title of this article there appears to be a distinct difference in attitudes towards food and eating between children and their mothers. While children have a more essential vision of food: 'we must eat to live', some mothers' are more hedonistic in their approach: 'we must live to eat'.

\section{Acknowledgements}

Both pieces of work discussed in this article were supported by grants from Kellogg's, France.

\section{Reference}

1 Bellisle F. et al. Three consecutive (1993, 1995, 1997) surveys of food intake, nutritional attitudes and knowledge, and lifestyle in 1000 French children aged 9-11 years. J. Hum. Nutr. Dietet. 2000; 13: 101-11. 